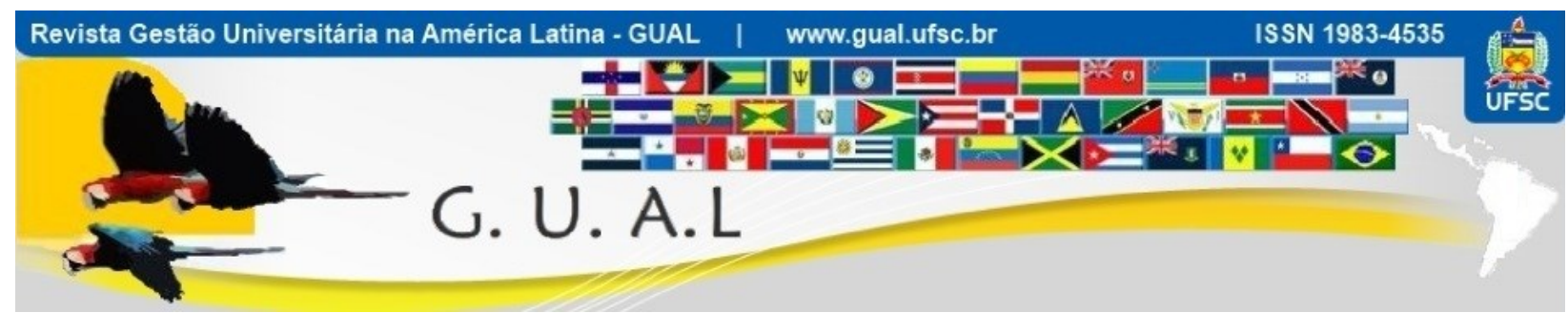

DOI: http://dx.doi.org/10.5007/1983-4535.2018v11n1p208

\title{
A HISTÓRIA E A EXPANSÃO DA EDUCAÇÃO A DISTÂNCIA: UM ESTUDO DE CASO DA UNICESUMAR
}

\section{THE HISTORY AND EXPANSION OF DISTANCE EDUCATION: A CASE STUDY OF UNICESUMAR}

Larissa Costa dos Santos, Bacharel Centro Universitário Cesumar - Unicesumar larissacosta7@,outlook.com

Cláudia Herrero Martins Menegassi, Doutora Centro Universitário Cesumar - Unicesumar Pesquisadora do ICETI - Instituto Cesumar de Ciência, Tecnologia e Inovação claudia.menegassi@unicesumar.edu.br

Recebido em 28/abril/2016

Aprovado em 17/outubro/2017

Sistema de Avaliação: Double Blind Review

Esta obra está sob uma Licença Creative Commons Atribuição-Uso. 


\title{
RESUMO
}

Com o advento da sociedade da informação, a tecnologia motivou novos comportamentos, atitudes e relações sociais, influenciando a vida em sociedade. A educação também foi uma das áreas que obteve mudanças motivadas pela tecnologia e uma das formas de educação onde essa realidade está mais presente é a Educação a Distância (EaD). Em vista disso, a presente pesquisa teve como objetivo descrever a história e a expansão da Educação a Distância no mundo e no Brasil e, ainda, descrever a história e a expansão da educação a distância em um caso específico: na instituição de ensino superior Unicesumar. Para tanto, foi realizada pesquisa qualitativa e a coleta de dados foi realizada por meio de pesquisa bibliográfica, análise de documentos da Unicesumar e entrevistas. Por fim, ressalta-se que a Educação a Distância no mundo, no Brasil e na instituição de ensino Unicesumar alcançaram notáveis avanços, contudo ainda há desafios a serem superados, devido ao fato de que ainda existem lugares onde não há acesso à educação e também trabalhar no combate ao preconceito que a modalidade sofre, visto que a Educação a Distância exerce uma função considerável no tocante a democratização do ensino.

Palavras-chave: Educação a Distância. História da Educação a Distância. História aa Educação a Distância no Mundo e no Brasil.

\begin{abstract}
With the advent of the information society, new technology motivated behaviors, attitudes and social relationships, influencing life in society. Education was also one of the areas that got changes driven by technology and one of the forms of education where this reality is more present is the Distance Education (EAD). In view of this, the present study aimed to describe the history and expansion of distance education in the world and in Brazil, and also describe the history and expansion of distance education in a specific case: the higher education institution Unicesumar. For this was carried out qualitative research and data collection was performed by means of literature, document analysis and interviews Unicesumar. Finally, it is noteworthy that the Distance Education in the world, in Brazil and Unicesumar educational institution achieved remarkable progress, but there are still challenges to be overcome due to the fact that there are still places where there is no access to education and also work to combat prejudice mode suffers, as the Distance Education plays a considerable role in relation to democratization of education.
\end{abstract}

Keywords: Distance Education. History of Distance Education. History of Education to Distance in the World and in Brazil. 


\section{INTRODUÇÃO}

Com o advento da sociedade da informação, a tecnologia aparece cada vez mais incorporada no cotidiano da sociedade. A tecnologia instituiu novos conceitos, comportamentos, atitudes e relações sociais e gerou uma nova ordem social, na qual não se consegue mais conceber a vida cotidiana desprovida do fator tecnológico. A educação também foi uma das áreas que obteve mudanças motivadas pela tecnologia. No presente, a distância entre as instituições de ensino e as pessoas não é mais um obstáculo. Com a tecnologia e os meios de comunicação a Educação a Distância (EaD) se tornou uma alternativa para quem está à procura de conhecimento e cursos formais.

Essa modalidade de ensino não ocorre exclusivamente por meio da internet, mas também por TV, rádio, jornais e a própria história da Educação a Distância é dividida em estágios por alguns autores pelo tipo de tecnologia adotada (VILAÇA, 2010). Segundo Vidal e Maia (2010), a primeira forma de ensino a distância foi aulas por correspondência, a escola responsável por isso foi a escola de línguas por correspondência, criada em 1856 por Charles Toussaint e Gustav Langenscheit.

No Brasil, o início da educação a distância aconteceu através do rádio e do papel impresso, no começo do século XX, já nos anos 90 a educação a distância ganha mais destaque com Projetos Pedagógicos Nacionais e em 1996 a EaD é inserida na legislação nacional (Lei $\mathrm{n}^{\circ}$ 9.394, de 20/12/1996), desse modo, obtendo o reconhecimento de uma nova modalidade de educação. Após isso, a EaD alcançou uma forte expansão, pois houve aumento no acesso às universidades através da nova modalidade. Uma das causas desse crescimento também se deve à criação da Universidade Aberta do Brasil (UAB) pelo Ministério da Educação (MEC), no ano de 2005. A UAB foi estabelecida com intuito de expandir a educação superior, no âmbito do Plano de Desenvolvimento da Educação.

Uma das instituições de ensino que oferece educação a distância é o Centro Universitário de Maringá - Unicesumar, cuja sede se localiza na cidade de Maringá, norte do estado do Paraná. Criada em 2006, a educação a distância da Unicesumar possui, segundo dados de 2015, 58 polos presenciais distribuídos em 11 estados brasileiros, além do Distrito Federal, 26 cursos de graduação e 21 cursos de pós-graduação, e é considerada a terceira melhor instituição de ensino privada, para realização da educação a distância (UNICESUMAR, 2015). 
Diante da expressividade dessa modalidade de educação superior na atualidade, o trabalho objetiva descrever a história e a expansão da educação a distância em sentindo amplo, ou seja, no mundo e no Brasil, e a experiência da Unicesumar, como Instituição que também colaborou para o desenvolvimento da EaD no país. Nesse contexto, essa pesquisa se justifica devido a necessidade de uma sistematização desse histórico para que se possa compreender, de fato, as origens, o desenvolvimento e a expansão desse fenômeno expressivo que se tornou a educação a distância.

Além disto, a pesquisa busca contribuir para futuros estudos e para maior compreensão a respeito da prática da Educação a Distância por meio do caso da EaD da Unicesumar, hoje, um Centro Universitário que possui, até o ano de 2015, 90 mil alunos, Índice Geral de Cursos 4, mais de 20 anos de existência e atuação na educação a distância desde 2006.

\section{CONCEITO DE EDUCAÇÃO A DISTÂNCIA}

A Educação a distância $(\mathrm{EaD})$ possui diversos conceitos, a maioria de caráter descritivo e que tem como base o ensino presencial. Para Maia e Mattar (2007, p. 6) "A EaD é uma modalidade de educação em que professores e alunos estão separados, planejada por instituições e que utiliza diversas tecnologias de comunicação".

Dentre vários conceitos, Moran (2002, p. 1) define a EaD como um:

[...] ensino/aprendizagem onde professores e alunos não estão normalmente juntos, fisicamente, mas podem estar conectados, interligados por tecnologias, principalmente as telemáticas, como a Internet. Mas também podem ser utilizados o correio, o rádio, a televisão, o vídeo, o CD-ROM, o telefone, o fax e tecnologias semelhantes.

Para Moore e Kearsley (2008) a EaD possui natureza multidimensional e eles adotam tal definição:

\footnotetext{
Educação a distância é o aprendizado planejado que ocorre normalmente em um lugar diferente do local do ensino, exigindo técnicas especiais de criação do curso e de instrução, comunicação por meio de várias tecnologias e disposições organizacionais e administrativas especiais (MOORE; KEARSLEY, 2008, p. 2).
}

Segundo Belloni (2009) o único que se diferencia desses conceitos já descritos é Otto Peters, a definição de Peters é baseada no paradigma econômico, isto é, para ele a Educação a Distância é um método de educação industrializado. 


\section{HISTÓRIA DA EDUCAÇÃO A DISTÂNCIA NO MUNDO}

As primeiras iniciativas em Educação a Distância foram singulares e isoladas (PETERS, 2009). Apesar de muitos considerarem que a Educação a Distância é uma metodologia de ensino recente, Gouvêa e Oliveira (2006) descrevem que esse tipo de ensino teve início com as epístolas de São Paulo no século I.

Peters (2009) destaca que apesar da Educação a Distância ter tido seu início no século I, foi na metade do século XIX que ocorreu o ápice da EaD em todo o mundo. Nos últimos 25 anos a EaD se desenvolveu de fato, devido a criação das Universidades Abertas e esse processo continua acelerado com o surgimento das universidades virtuais.

\subsection{PRIMEIRA GERAÇÃO DA EDUCAÇÃO A DISTÂNCIA}

De acordo com Maia e Mattar (2007) foi na metade do século XIX, motivada pelo desenvolvimento da comunicação e dos meios de transportes, que surge de fato a Educação a Distância. Moore e Kearsley (2008) ressaltam que, comumente, a primeira geração é denominada estudo por correspondências, porém, na época era chamada de estudo em casa pelas escolas com fins lucrativos e pelas universidades era intitulada estudo independente. $\mathrm{O}$ ensino por correspondência, segundo Peters (2009), foi utilizado por países que eram grandes, mas que tinham pouca densidade populacional, como a Argentina, o Canadá e a Austrália.

Segundo Guarezi e Matos (2012), o período de 1728 até meados de 1970 é definido como a primeira geração da EaD. Nessa geração os estudos eram realizados por meio de correspondências, os principais meios de comunicação eram materiais impressos em forma de guia de estudos com tarefas e o relacionamento entre o aluno e a instituição de ensino era limitado.

De acordo com Alves (2009), o primeiro anúncio de aulas por correspondência foi feito por Caleb Philips em 1728 na Gazeta de Boston, Philips enviava semanalmente as lições para os alunos. Segundo Lopes e Faria (2013) o curso oferecido por Philips era de taquigrafia. Conforme Vidal e Maia (2010), no ano de 1856 na cidade de Berlim foi criada por Charles Toussaint e Gustav Langenscheit a primeira escola de línguas por correspondência. No ano de 1892 houve uma tentativa de formar professores para as escolas paroquiais por correspondências; o curso era oferecido pela Universidade de Chicago. A partir disso, vários países começaram a praticar a Educação a Distância, tendo o material impresso e os correios como recursos para disseminação do conhecimento. 


\section{A HISTÓRIA E A EXPANSÃO DA EDUCAÇÃO A DISTÂNCIA: UM ESTUDO DE CASO DA \\ UNICESUMAR \\ DOI: http://dx.doi.org/10.5007/1983-4535.2018v11n1p208}

Moore e Kearsley (2008) ressaltam que em 1881 foi fundada a Chautauqua Correspondence College, que em 1883 teve seu nome alterado para Chautauqua Correspondence College. Essa foi a primeira instituição a utilizar o correio para os cursos de nível superior. Na década de 1930, Guarezi e Matos (2012) identificaram a existência de 39 universidades norte-americanas que ofertavam cursos por correspondência, e no mesmo período houve a Primeira Conferência Internacional sobre Correspondência no Canadá e foi criado o Centro Nacional de EaD na França, para atender os refugiados da guerra.

\subsection{SEGUNDA GERAÇÃO DA EDUCAÇÃO A DISTÂNCIA}

No começo dos anos de 1960 as universidades europeias e as de outros continentes começaram a atuar na educação secundária e superior. Foi nesse momento que a Educação sofreu um avanço significativo e deu início à segunda geração da $\mathrm{EaD}$ que teve fim no começo da década de 1990 (VIDAL; MAIA, 2010).

Segundo Maia e Mattar (2007) a segunda geração tem como característica a utilização de novas mídias, como televisão, rádio, fitas de áudio, vídeo, telefone e também a criação das universidades abertas de ensino a distância. Peters (2009) caracteriza a segunda geração inicialmente pelo uso de dois meios de comunicação: rádio e televisão. Depois de algum tempo houve a introdução dos vídeos e das fitas cassetes.

Pereira e Moraes (2010) relatam que o material impresso continuou a ser utilizado, no entanto, a partir dessa geração começou a também ter emissões radiofônicas, de televisão e apresentação de vídeos. Peters (2009) destaca que a utilização das tecnologias ocorria de maneira associada entre elas e não separada. De acordo com Maia e Mattar (2007) nessa geração um fato considerável foi a criação da Open University em 1969, uma universidade aberta de ensino a distância britânica que fazia o uso de rádio, televisão, vídeos, fitas cassetes, pois, a partir da sua fundação foram criadas, influenciadas pelo modelo da Open University, outras universidades abertas de ensino a distância (MAIA; MATTAR, 2007).

Peters (2009) salienta que as universidades autônomas foram criadas, pois os governos a partir delas poderiam implementar suas políticas educacionais. Algumas universidades aceitavam alunos que não estavam qualificados e esses aspectos mudaram o cenário da Educação a Distância. O mesmo autor afirma que a Educação a Distância a partir desse momento passou a ser caracterizada como um ensino que possibilitava acesso à educação para grupos maiores de adultos. 


\subsection{TERCEIRA GERAÇÃO DA EDUCAÇÃO A DISTÂNCIA}

A terceira geração da $\mathrm{EaD}$ representa o Modelo de aprendizagem a distância por Conferência. Nessa geração houve a introdução de novas tecnologias nos ambientes de aprendizagens, provocando desse modo a criação de uma nova imagem da educação (PEREIRA; MORAES, 2010).

A partir de 1990, Guarezi e Matos (2012) afirmam que foi o período em que a terceira geração teve início e houve a introdução de videotexto, do computador, da tecnologia multimídia, do hipertexto e de redes de computadores. As mídias utilizadas na geração passada se integraram nessa geração e a Educação a Distância passou a ser caracterizada como online. Para Lopes e Faria (2013) nos anos de 1990 teve início o quarto período da EaD no mundo e o mesmo tem como características a utilização da rede no processo de ensino e aprendizagem. Segundo Maia e Mattar (2007) essa geração seria e foi marcada pelo desenvolvimento das tecnologias da informação em 1995 com a expansão da internet. A partir disso surgiram os ambientes virtuais da aprendizagem e também associações de instituições de ensino a distância.

\section{EDUCAÇÃO A DISTÂNCIA NO BRASIL}

A Educação a Distância no Brasil tem um histórico marcado por progresso e retrocessos devido ao fato de não existir políticas públicas para o setor. Até os anos de 1970 o Brasil era um dos países que estava entre as principais nações no mundo em relação ao desenvolvimento da $\mathrm{EaD}$, no entanto, a partir dessa década outros países avançaram e o Brasil estagnou e voltou a progredir no final da década de 1990 (ALVES, 2009). Segundo Costa (2013) o avanço ocorrido no final do milênio se deve a aprovação em 1996 da Lei de Diretrizes e Bases da Educação Nacional (LDB) - Lei na 9394/96 (BRASIL, 1996), que reconheceu a Educação a Distância no Brasil e trouxe reinvindicações de políticas e estratégias para que as Instituições de Ensino Superior (IES) do país executassem e estabelecessem o ensino a distância.

\subsection{FASE INICIAL DA EDUCAÇÃO A DISTÂNCIA NO BRASIL}

Segundo Maia e Mattar (2007), a Educação a Distância no Brasil começou com a utilização das correspondências, como ocorreu em outros países. Entretanto, alguns autores 


\section{A HISTÓRIA E A EXPANSÃO DA EDUCAÇÃO A DISTÂNCIA: UM ESTUDO DE CASO DA

defendem que a $\mathrm{EaD}$ no Brasil teve sua origem através do rádio e não da correspondência (GUAREZI; MATOS, 2012).

Alves (2009) relata que pesquisas realizadas pelo Instituto de Pesquisa em Estatística Aplicada (IPEA) revelam que no final do século XIX já havia oferta de cursos de datilografia por correspondência no Rio de Janeiro e as aulas eram ministradas por professores particulares. No entanto, o marco oficial ocorreu em 1904 com a instalação das Escolas Internacionais (ALVES, 2009).

Maia e Mattar (2007) afirmam que as escolas ofertavam cursos por correspondências em jornais. As instituições eram privadas, representavam organizações dos Estados Unidos da América e ofereciam cursos pagos na língua espanhola. Lopes e Faria (2013) apontam que as responsáveis por determinar a fase inicial da Educação a Distância no país foram as escolas internacionais.

A Educação a Distância nessa época tinha pouca importância e sofria dificuldades na utilização dos correios (MAIA; MATTAR, 2007). Alves (2009) destaca que o ensino por correspondência se manteve como única modalidade durante vinte anos no Brasil.

\subsection{FASE INTERMEDIÁRIA DA EDUCAÇÃO A DISTÂNCIA NO BRASIL}

A segunda fase ou fase intermediária da Educação a Distância foi marcada pela tecnologia (LOPES; FARIA, 2013). Alves (2009) afirma que através de uma iniciativa privada foi criada a Rádio Sociedade do Rio de Janeiro em 1923 e proporcionar educação a todos era o principal propósito da emissora. Conforme Maia e Mattar (2007) a rádio teve como mentores Henrique Morize e Roquette-Pinto e disponibilizava cursos de português, francês, literatura francesa, radiotelegrafia, telefonia e outros.

De acordo com Lopes e Faria (2013) a Rádio Sociedade do Rio de Janeiro em 1936 foi doada ao Ministério da Educação e da Saúde, em decorrência das exigências feitas de difícil execução, considerando que a rádio não possuía fins comerciais. E em 1937, segundo Maia e Mattar (2007) surgiu o Serviço de Radiodifusão Educativa do Ministério da Educação. Lopes e Faria (2013) afirmam que a segunda fase da Educação a Distância no Brasil foi confirmada com a criação de alguns Institutos na metade do século XX, e outras organizações.

A Universidade do Ar (UNAR) criada em 1947, foi fundada pelo Serviço Nacional de Aprendizagem Comercial (SENAC), pelo Serviço Social de Comércio (SESC) e por emissoras associadas (MAIA; MATTAR, 2007). Alves (2009) relata que a Universidade foi 


\section{A HISTÓRIA E A EXPANSÃO DA EDUCAÇÃO A DISTÂNCIA: UM ESTUDO DE CASO DA \\ UNICESUMAR \\ DOI: http://dx.doi.org/10.5007/1983-4535.2018v11n1p208}

desenvolvida no Rio de Janeiro e em São Paulo, entretanto no ano de 1950 já estava presente em 318 localidades. As aulas aconteciam por meio de uma rede de emissoras, entre elas a Rádio Tupi e a transmissão era ao vivo (LOPES; FARIA, 2013).

A UNAR ofertava cursos comerciais radiofônicos e os materiais que os alunos utilizavam eram apostilas e monitores. As atividades da UNAR foram encerradas em 1961 (MAIA; MATTAR, 2007). Para Lopes e Faria (2013) através da Universidade do Ar a Educação a Distância sofreu uma expansão, devido à utilização do rádio em seu método de ensino, tendo em vista que o rádio possui uma grande abrangência e isso fez com que um maior número de pessoas tivesse acesso aos cursos

Alves (2009) destaca que outro projeto importante foi o Movimento Brasileiro de Alfabetização (MOBRAL), o governo federal era associado ao MOBRAL e este tinha alcance nacional pelo fato de usar o rádio. Beluzo e Toniosso (2015) destacam que o MOBRAL possuía metas, como:

[...] erradicar o analfabetismo, integrar os analfabetos na sociedade, dar oportunidades a eles através da educação, buscando assim, benefícios para a população menos favorecida economicamente e principalmente a alfabetização funcional, com a aquisição de técnicas elementares de leitura, escrita e cálculos matemáticos (BELUZO; TONIOSSO, 2015, p. 200).

De acordo com Lopes e Faria (2013) a Educação a Distância no Brasil teve várias iniciativas desde o seu início, porém, foi a partir dos anos 60 que a $\mathrm{EaD}$ cresceu de forma mais intensa. A EaD passou a ter mais expressão nessa década, pois foi a partir dela que foi registrada a utilização da televisão em programas de EaD no Brasil. A televisão educativa teve vários incentivos no Brasil, principalmente nas décadas de 1960 e 1970. Em 1967 o Código Brasileiro de Telecomunicações impôs a transmissão de programas educativos tanto pelas emissoras de rádio quanto para as televisões educativas (ALVES, 2009).

Em 1967, o Projeto Satélite Avançado de Comunicações Interdisciplinares (SACI) foi gerado de forma experimental e a finalidade do projeto era de elaborar um sistema nacional de telecomunicações com o uso de satélite (MAIA; MATTAR, 2007). O projeto se manteve por um curto período, no entanto é considerado a primeira experiência televisiva por satélite para fins educacionais (GUAREZI; MATOS, 2012).

Apesar das inúmeras iniciativas, a maioria das transmissões ocorria em horários que não eram compatíveis com os horários que os alunos estavam disponíveis, devido a isso os canais abertos de televisão não tiveram bons resultados (ALVES, 2009). Um fato positivo, 
segundo Alves (2009), foi a criação de alguns programas como os telecursos, hoje denominado Telecurso 2000 pela Fundação Roberto Marinho, os cursos tiveram êxito e são oferecidos até hoje pela instituição.

$\mathrm{Na}$ Universidade de Brasília (UNB) foi criado o Centro de Educação Aberta e a Distância (CEAD), uma entidade que trabalha desde 1979 com a EaD e oferece cursos de educação continuada a distância (LOPES; FARIA, 2013). Saraiva (1996) destaca que a Universidade de Brasília iniciou sua experiência na EaD, oferecendo mais de vinte cursos, sendo que seis eram traduzidos dos cursos da Open University e pessoas de todos os estados tiveram acesso a esses cursos.

Em 1996 é oficializado a Educação a Distância no Brasil com a promulgação da Lei de Diretrizes e Bases da Educação Nacional - Lei n. 9.393, 20 de dezembro de 1996 - essa lei foi normatizada por tais decretos: Decreto n. 2.494 (1998), Decreto n. 2561 (1998) e pela Portaria Ministerial n. 301 (1998) (MAIA; MATTAR, 2007).

Guarezi e Matos (2012) ressaltam que o governo federal também participou de ações, uma delas teve a parceria da Fundação Roquette Pinto, foi criado o programa Um Salto para o Futuro. Lopes e Faria (2013) complementam que no ano de 1990 o Ministério da Educação (MEC) e a Fundação juntos criaram o programa na intenção de promover qualificação de professores do ensino fundamental, empregando o uso de televisão via satélite, transmissão ao vivo em horários e dias prefixados.

No final dos anos 1990 a Educação a Distância sofre um retrocesso, pois as emissoras foram exoneradas de exibir programas educativos (LOPES; FARIA, 2013).

\subsection{FASE MODERNA DA EDUCAÇÃO A DISTÂNCIA NO BRASIL}

$\mathrm{Na}$ fase moderna três organizações foram determinantes na história da Educação a Distância no Brasil, são elas: a Associação Brasileira de Teleducação - ABT, o Instituto de Pesquisas Avançadas em Educação - IPAE e a Associação Brasileira de Educação a Distância - ABED (ALVES, 2009). A ABT foi criada no ano de 1991, por uma equipe de profissionais na área de radiodifusão e logo no início das atividades agrupou os melhores profissionais brasileiros e estrangeiros que trabalhavam com tecnologia na educação e executou a série dos Seminários Brasileiros de Tecnologias Educacional. A associação foi pioneira na oferta de programas de pós-graduação a distância e também colaborou na definição de diversas políticas públicas (ALVES, 2009). 


\section{A HISTÓRIA E A EXPANSÃO DA EDUCAÇÃO A DISTÂNCIA: UM ESTUDO DE CASO DA \\ UNICESUMAR \\ DOI: http://dx.doi.org/10.5007/1983-4535.2018v11n1p208}

O IPAE criado em 1973 contribui com a difusão da Educação a Distância e maior compreensão dela por parte da sociedade. Pode-se destacar os primeiros Encontros Nacionais de Educação a Distância ocorrido em 1989 e os Congressos Brasileiros de Educação a Distância em 1993, ambos promovidos pela instituição. A elaboração das disposições normativas incluídas à LDB também foi de responsabilidade do Instituto (ALVES, 2009).

A ABED foi criada em 1995 por um grupo de educadores que tinham interesse em tecnologias de aprendizagem e em Educação a Distância e é considerada uma sociedade científica sem fins lucrativos e tem como missão: "Contribuir para o desenvolvimento do conceito, métodos e técnicas que promovam a educação aberta flexível e a distância" (ABED, 2015).

A Associação, segundo Alves (2009), é uma entidade primordial, pois propicia o desenvolvimento da EaD no Brasil, a organização e articulação entre profissionais e instituições não só no país como no exterior. O autor destaca a relevância prática da instituição, por ser ela a responsável pela organização de congressos, encontros entre outros eventos de $\mathrm{EaD}$.

Outra instituição importante é a Universidade Aberta do Brasil (UAB) criada pelo Ministério da Educação (MEC) no ano de 2005. A UAB foi estabelecida com intuito de expandir a educação superior, no âmbito do Plano de Desenvolvimento da Educação. A UAB foi criada em 2005 e oficializada pelo Decreto n. 5.800 de 8 de junho de 2006 como "um consórcio de Instituições Públicas de Ensino Superior, Estados e Municípios, coordenado pela Secretaria de Educação a Distância do Ministério da Educação" (MAIA; MATTAR, 2007, p. 43). Essa e outras iniciativas que ocorrem atualmente no Brasil, através do MEC, como o projeto de inclusão digital, o Proinfo, a Escola Técnica Aberta do Brasil e outros dão a Educação a Distância novas perspectivas (GUAREZI; MATOS, 2012).

\section{METODOLOGIA}

$\mathrm{Na}$ fase moderna três organizações foram determinantes na história da Educação a Distância no Brasil, são elas: a Associação Brasileira de Teleducação - ABT, o Instituto de Pesquisas Avançadas em Educação - IPAE e a Associação Brasileira de Educação a Distância - ABED (ALVES, 2009). A ABT foi criada no ano de 1991, por uma equipe de profissionais na área de radiodifusão e logo no início das atividades agrupou os melhores profissionais brasileiros e estrangeiros que trabalhavam com tecnologia na educação e executou a série dos 
Seminários Brasileiros de Tecnologias Educacional. A associação foi pioneira na oferta de programas de pós-graduação a distância e também colaborou na definição de diversas políticas públicas (ALVES, 2009).

O IPAE criado em 1973 contribui com a difusão da Educação a Distância e maior compreensão dela por parte da sociedade. Pode-se destacar os primeiros Encontros Nacionais de Educação a Distância ocorrido em 1989 e os Congressos Brasileiros de Educação a Distância em 1993, ambos promovidos pela instituição. A elaboração das disposições normativas incluídas à LDB também foi de responsabilidade do Instituto (ALVES, 2009).

A ABED foi criada em 1995 por um grupo de educadores que tinham interesse em tecnologias de aprendizagem e em Educação a Distância e é considerada uma sociedade científica sem fins lucrativos e tem como missão: "Contribuir para o desenvolvimento do conceito, métodos e técnicas que promovam a educação aberta flexível e a distância" (ABED, 2015).

A Associação, segundo Alves (2009), é uma entidade primordial, pois propicia o desenvolvimento da $\mathrm{EaD}$ no Brasil, a organização e articulação entre profissionais e instituições não só no país como no exterior. O autor destaca a relevância prática da instituição, por ser ela a responsável pela organização de congressos, encontros entre outros eventos de EaD.

Outra instituição importante é a Universidade Aberta do Brasil (UAB) criada pelo Ministério da Educação (MEC) no ano de 2005. A UAB foi estabelecida com intuito de expandir a educação superior, no âmbito do Plano de Desenvolvimento da Educação. A UAB foi criada em 2005 e oficializada pelo Decreto n. 5.800 de 8 de junho de 2006 como "um consórcio de Instituições Públicas de Ensino Superior, Estados e Municípios, coordenado pela Secretaria de Educação a Distância do Ministério da Educação" (MAIA; MATTAR, 2007, p. 43). Essa e outras iniciativas que ocorrem atualmente no Brasil, através do MEC, como o projeto de inclusão digital, o Proinfo, a Escola Técnica Aberta do Brasil e outros dão a Educação a Distância novas perspectivas (GUAREZI; MATOS, 2012). 


\section{ANÁLISE E DISCUSSÃO DOS DADOS}

Com o intuito de atender o último objetivo específico, ou melhor, descrever a história da Educação a distância na Unicesumar, este capítulo tem como finalidade expor a trajetória da Educação a Distância da Unicesumar por meio dos dados coletados através de documentos e entrevistas.

O presente capítulo foi estruturado em três seções principais: na primeira é apresentada o perfil dos entrevistados, na segunda é exposta uma breve caracterização da Instituição de ensino e na última a história da EaD na Unicesumar.

\subsection{PERFIL DOS ENTREVISTADOS}

Neste estudo foi realizado um total de quatro entrevistas e essas ocorreram nos meses de outubro e novembro de 2015.

A primeira entrevista foi realizada com a Coordenadora Pedagógica do curso de Graduação em Pedagogia na modalidade a distância.

O segundo entrevistado foi um dos pioneiros da modalidade Educação a Distância na Unicesumar. Foi também o professor responsável da Unicesumar junto ao MEC para assuntos de $\mathrm{EaD}$ e coordenador dos dois primeiros cursos reconhecido pelo MEC: o curso de Graduação e Pós-Gradução (Lato sensu) ambos em Gestão do Agronegócio.

A terceira entrevista ocorreu com o Pró-Reitor da Educação a Distância da instituição. E o último entrevistado foi o diretor de Planejamento de Ensino do Núcleo de Educação a Distância do Centro Universitário de Maringá - Unicesumar e também considerado um dos precursores da Educação a Distância na Unicesumar.

Com o intuito de manter a privacidade dos entrevistados, foi empregado um sistema de códigos neste trabalho. Isto posto, os entrevistados estão identificados respectivamente como E1, E2, E3 e E4.

\subsection{O CENTRO UNIVERSITÁRIO DE MARINGÁ - UNICESUMAR}

A Unicesumar foi fundada em 1986 e sua sede é localizada na cidade de Maringá PR. A oferta de ensino superior começou no ano de 1990 com a implantação do primeiro curso, o de Administração. Em 2002, a instituição se tornou Centro Universitário de Maringá com o aval do Ministério da Educação (UNICESUMAR, 2014). 


\section{A HISTÓRIA E A EXPANSÃO DA EDUCAÇÃO A DISTÂNCIA: UM ESTUDO DE CASO DA \\ UNICESUMAR \\ DOI: http://dx.doi.org/10.5007/1983-4535.2018v11n1p208}

No que diz respeito à Educação a Distância na Unicesumar, tema tratado nessa pesquisa, esta teve início em 2006, com o credenciamento junto ao Ministério da Educação. Até a data de realização desta pesquisa, a instituição possui 58 polos. Na atualidade a Unicesumar possui cursos tanto na modalidade presencial como a distância. Os cursos de graduação que a instituição oferta são bacharelados, licenciaturas e tecnólogos. Oferece também Pós-Graduação lato sensu com diversos cursos e quatro Programas de Pós-Graduação Stricto Sensu, todos recomendados pela Coordenação de Aperfeiçoamento de Pessoal de Nível Superior (CAPES) (UNICESUMAR, 2014).

A missão da Unicesumar é "promover a educação de qualidade nas diferentes áreas do conhecimento, formando profissionais cidadãos que contribuam para o desenvolvimento de uma sociedade justa e solidária" (UNICESUMAR, 2015).

\subsection{HISTÓRIA DA EaD -UNICESUMAR}

Nesta seção será abordada a história do Núcleo a Distância da Unicesumar, utilizando as entrevistas realizadas e os documentos analisados. Vale salientar que não é um relato completo, mas, de aspectos considerados importantes pelos entrevistados.

\subsubsection{INÍCIO DA HISTÓRIA DA EDUCAÇÃO A DISTÂNCIA NA UNICESUMAR}

A história da Educação a Distância na Unicesumar teve início em 2006 com o credenciamento da instituição e a oferta de cursos, conforme afirma E1. Por outro lado, E3 destaca que o Ensino a Distância começou antes de 2006, através de um evento realizado pela Associação Nacional dos Centros Universitários - ANACEL na instituição. Segundo E3, no evento foi comentado sobre a Educação a Distância que até o momento era algo novo e não havia muitas instituições de ensino que trabalhavam com EaD.

Algo evidenciado por E4 foi o fato de que a palestra sobre Educação a Distância ministrada no evento da ANACEL foi realizada pelo Rubens Martins - Secretário de regulação da Educação a Distância -, naquele tempo o reitor não tinha interesses na Educação a Distância, mas Martins sugeriu ao reitor da instituição se credenciar a EaD "se não ele perderia o bonde da história".

E2 complementa considerando que um dos fatos de ter implantado a $\mathrm{EaD}$ na Unicesumar foi por causa de uma das concorrentes da instituição, na época, estar ganhando mercado nesse segmento. Desde então começou o trabalho de estruturação da Educação a 
Distância na Unicesumar, conforme E4 foi organizado um grupo responsável pelo desenvolvimento de um plano para o credenciamento da EaD na instituição, o grupo era composto por ele, por mais um professor e duas professoras.

Nesse momento, segundo E3 a construção de materiais, projeto pedagógico se inicia e todo o processo foi auxiliado pela consultoria contratada. Foi protocolado o pedido e no ano de 2006 a Unicesumar obteve autorização para curso de pós-graduação e em 2007 o Ministério da Educação autorizou a abertura dos cursos de graduação. E3 avalia que o início da EaD na Unicesumar foi gradual, de forma que fosse preservada a qualidade do ensino. E4 complementa que o crescimento da $\mathrm{EaD}$ na instituição foi aos poucos: "e aí foi crescendo, ano a ano, abrindo novos cursos de graduação, como a gente é Centro Universitário, temos autonomia universitária para abrir os cursos" (E4).

E4 afirma que com o decorrer da história houve avanços e estruturação da equipe e quanto ao desenvolvimento da instituição na Ead, o mesmo afirma que o aprendizado ocorreu com a prática e com visitas a instituições que já tinham cursos na modalidade de Educação a Distância.

\subsubsection{OBJETIVOS DA INSTITUIÇÃO QUANTO À OFERTA DE CURSOS NA EDUCAÇÃO A DISTÂNCIA}

No tocante aos objetivos da Instituição quanto à oferta de cursos na Educação a Distância, E1 afirma que a criação da Educação a Distância na Unicesumar foi avaliada como uma estratégia de mercado e complementa que a Educação a Distância ganha em quantidade de alunos, isto é, em escala, visto que o número de discentes na $\mathrm{EaD}$ é muito maior que no ensino presencial. E3 avalia que o início da EaD na Unicesumar se deve ao fato de que uma instituição de ensino deve estar sempre a frente, inovar, fazer algo que a minoria realiza.

\subsubsection{DIFICULDADES ENFRENTADAS PELA UNICESUMAR E SUAS ESTRATÉGIAS QUANTO A NOVA MODALIDADE}

A implementação da Educação a Distância na instituição fez com que surgissem novas dificuldades. Sobre essa experiência, E1 relata que uma das maiores dificuldades foi o prejulgamento que faziam da $\mathrm{EaD}$ como uma modalidade de ensino inferior, nos dias atuais ainda existe preconceito quanto a modalidade, entretanto é menor devido os índices e notas [ENADE, IGC] que a Instituição possui que está igual ou superior ao presencial. 


\section{A HISTÓRIA E A EXPANSÃO DA EDUCAÇÃO A DISTÂNCIA: UM ESTUDO DE CASO DA \\ UNICESUMAR \\ DOI: http://dx.doi.org/10.5007/1983-4535.2018v11n1p208}

Por outro lado, para E3 as dificuldades também foram em questões operacionais e até mesmo com os docentes, no que se refere aos problemas operacionais E3 destaca a primeira transmissão: "[...] foi de uma maneira arcaica comparada ao que a gente tem hoje, não foi com a melhor câmera, não foi com a melhor mesa" (E3). Outra dificuldade evidenciada pelo mesmo entrevistado foi com os docentes, o mesmo afirma que os professores presumiam que poderiam perder o papel no ensino e aprendizagem por causa da tecnologia e devido a isso houve resistência por parte dos professores quanto a Educação a Distância.

Quanto a alcançar mercado para a nova oferta E3 destaca que também foi um processo árduo, entretanto, já melhorou muito a questão do preconceito com o Ensino a Distância, porém, E3 afirma que no presente tem a visão do empregador que ainda possui certa rejeição quanto aos candidatos que são formados pela $\mathrm{EaD}$.

No que se refere ao MEC, E4 menciona que a instituição em nenhum momento teve grandes problemas, conforme o entrevistado o trabalho sempre foi realizado com responsabilidade. Cenário diferente enfrentado pelas concorrentes da época, segundo E1 várias instituições fecharam pelo fato de não serem organizações corretas. Hoje, o Núcleo de Educação a Distância conta com oito diretorias, de acordo com E4 essa estruturação ocorreu para que cada um pudesse cuidar de uma parte específica e de certa forma os problemas fossem amenizados.

\subsubsection{CONTRATAÇÃO E CAPACITAÇÃO DOS DOCENTES PARA O NÚCLEO DE EDUCAÇÃO A DISTÂNCIA (NEaD) DA UNICESUMAR}

E1 aborda este assunto e destaca que no início havia os professores que eram de certa maneira "temporários", isto é, eram contratados somente por um determinado período, diferente de hoje que a maior parte dos docentes são contratados.

Quanto à capacitação, no início da EaD na Unicesumar, E4 afirma que: “[...] a gente buscou isso, vieram pessoas aqui, teve apoio de uma consultoria em 2005, indicada por uma pessoa que o reitor conhecia, mas a gente sempre buscou" (E4). E1 destaca que no começo quem dava orientações eram os próprios coordenadores dos cursos, algo diferente do que ocorre nos dias atuais. 


\subsubsection{TIPOS DE PROFESSORES NA INSTITUIÇÃO}

No presente, há quatro tipos de professores na Unicesumar, o professor conteudista, o professor formador, o mediador e o tutor online. De acordo com E1, o professor conteudista é aquele que elabora o livro que será utilizado no curso e o que gravam as aulas conceituais, diferente do professor formador que é responsável pela aula ao vivo.

Já com relação ao outro tipo de professor, o professor mediador, E1 afirma que é um professor que necessita ser um especialista, é responsável pela correção das provas, atendimento aos alunos e acompanha o professor formador no estúdio, entres outras funções. Quando questionada acerca do tutor online E1 ressalta que essa ocupação existe há cerca de três anos, sua criação foi consequência do crescimento no número de alunos.

No que diz respeito a Unicesumar fazer uso da nomenclatura mediador ao invés de tutor como utiliza o Ministério da Educação. E2 destaca que "aos meus olhos, utilizou-se a nomenclatura de um modelo presencial, assim como hoje ainda existem os moderadores em congressos e debates" (E2). Conforme E4 esse aspecto ainda é muito discutido pelo fato da tutoria não ser regulamentada e cada instituição administra da sua forma, entretanto mediador é só uma convenção da Unicesumar, quando o Ministério da Educação avalia a instituição ajusta a nomenclatura para tutor.

\subsubsection{O FATOR TECNOLOGIA DA EDUCAÇÃO A DISTÂNCIA NA UNICESUMAR}

O aspecto tecnológico foi o mais discutido, de acordo com E2, pois não sabia ao certo qual seria a maneira que isso ia ser proporcionado ao aluno. Para E1, a tecnologia teve bastante problemas e destaca que no presente momento o contexto é muito diferente do que no passado, alguns problemas relatados pela entrevistada eram o fato de só ter um estúdio, quando as aulas eram ao vivo a transmissão "caía”, entre outros. Nos dias atuais, através dos investimentos, E1 destaca que houve avanços e o sistema proporciona muito mais informações sobre os alunos e sua vida acadêmica.

E4 também aborda as dificuldades enfrentadas no início com relação a tecnologia e destaca que até hoje ainda é uma questão desafiadora. Mas complementa afirmando que mesmo com os problemas houve investimentos como ainda tem e dessa forma ocorreram grandes avanços. 


\subsubsection{MOMENTO ATUAL DA EDUCAÇÃO A DISTÂNCIA NA UNICESUMAR}

Depois de quase uma década atuando no mercado com a Educação a Distância, a Unicesumar está entre as três melhores instituições de EaD do Brasil. Com o intuito de exercer a responsabilidade social o Núcleo de Educação a Distância da Unicesumar tem como objetivo geral: "Promover e democratizar o acesso da sociedade ao conhecimento por meio eletrônico, confirmando e ampliando as oportunidades de desenvolvimento" (UNICESUMAR, 2014. p. 16).

$\mathrm{Na}$ atualidade, a Unicesumar na modalidade $\mathrm{EaD}$ oferece um total de 47 cursos, sendo 26 cursos de graduação, considerando tecnólogos, licenciaturas e bacharelados e 21 cursos de pós-graduação, como, MBA ou especialização são cursos nas mais diversas áreas do conhecimento e todos modulares. A Unicesumar possui polos em 13 estados, sendo que nos estados de Minas Gerais, Paraná, Santa Catarina são os locais que possuem maior quantidade de polos (UNICESUMAR, 2015).

Quanto à estrutura do Núcleo de Educação a Distância da Unicesumar-Sede, esta, ocupa uma área de 3 mil m² e essa estrutura está destinada a Pró-Reitoria, as diretorias, conta também com área para produção de matérias, secretaria acadêmica, sala de tutoria, sala de professores formadores, estúdio de Tv e polo de apoio presencial (UNICESUMAR, 2014).

No tocante as perspectivas da Educação a Distância, E3 afirma que o maior desafio será em não ter mais a Educação a Distância, mas sim a Educação Híbrida, na qual o ensino será ofertado de maneira que algumas disciplinas serão a distância e outras no presencial. E E4 parte do mesmo princípio e ressalta que num futuro próximo não haverá mais a divisão de modalidades e sim a junção delas.

\section{CONSIDERAÇÕES FINAIS}

O presente estudo teve como objetivo geral: "Descrever a história e a expansão da Educação a Distância em sentido amplo e a experiência da Unicesumar". Pretendeu-se sistematizar o histórico para que se possa compreender, de fato, as origens, o desenvolvimento e a expansão desse fenômeno tão importante que se tornou a educação a distância e também contribuir para futuros estudos e acrescentar maior compreensão a respeito da educação a distância através da história da Unicesumar, hoje, um Centro Universitário que possui 90 mil alunos, Índice Geral de Cursos 4, mais de 20 anos de existência e atuação na educação a distância desde 2006. 


\section{A HISTÓRIA E A EXPANSÃO DA EDUCAÇÃO A DISTÂNCIA: UM ESTUDO DE CASO DA \\ UNICESUMAR \\ DOI: http://dx.doi.org/10.5007/1983-4535.2018v11n1p208}

Assim sendo, a presente pesquisa demonstrou que a trajetória da Educação a Distância no mundo e no Brasil ocorreu de forma progressiva, alguns autores defendem que foi no século I que a $\mathrm{EaD}$ teve seu início, entretanto, foi no século XIX estimulada pelo desenvolvimento dos meios de comunicação e transporte que a modalidade se estabeleceu com o começo da Primeira Geração, também intitulada Ensino por Correspondência, a partir desse momento, junto com os avanços tecnológicos a EaD obteve progresso.

Outros fatores que contribuíram no estabelecimento da Educação a Distância foi a criação de organizações, instituições de ensino, como as Universidades Abertas que faziam uso da modalidade e até mesmo as instituições que empregava o ensino tradicional, mas incorporaram a EaD em seu método de ensino e colaboraram a difundir a modalidade. No Brasil também houve a Lei de Diretrizes e Bases da Educação Nacional (LDB) que em 1996 reconheceu a EaD como uma modalidade de educação e demanda das Instituições de Ensino Superior políticas e estratégias para consolidar a EaD no país.

Quanto a história da Educação a Distância no Centro Universitário de Maringá Unicesumar, nota-se que o início ocorreu em 2006 e sucedeu de modo cauteloso, a iniciativa de se ter um núcleo de $\mathrm{EaD}$ na instituição foi motivada por aspectos mercadológicos, isto é, atender a uma nova demanda do mercado, mas também de inovação. No início a IES não dispunha dos melhores recursos para ofertar a modalidade, contudo depois de um crescimento sustentável, na atualidade a organização é contemplada de uma estrutura completa, equipamentos modernos, mão de obra qualificada, modelo pedagógico estabelecido e nos dias atuais é considerada a terceira melhor instituição de ensino privada para realização da educação a distância.

Por fim, ressalta-se que a Educação a Distância no mundo, no Brasil e na instituição de ensino Unicesumar alcançaram notáveis avanços, contudo ainda há desafios a serem superados, devido ao fato de que ainda existem lugares onde não há acesso à educação e também trabalhar no combate ao preconceito que a modalidade sofre, visto que a Educação a Distância exerce uma função considerável no tocante a democratização do ensino.

\section{REFERÊNCIAS}

Associação Brasileira de Educação a Distância - ABED. Disponível em:

$<\mathrm{http}: / / \mathrm{www}$.abed.org.br/site/pt/institucional/missao/>. Acesso em: 06 ago. 2015 
ALVES, J. R. M. A história da EaD no mundo. In: LITTO, F.; FORMIGA, M. (orgs.). Educação a distância: O estado da arte. São Paulo: Pearson Education do Brasil, 2009. Disponível em:

$<$ http://cesumar.bv3.digitalpages.com.br/users/publications/9788576051978/pages/_1>. Acesso em: 20 maio 2015.

BELLONI, M. L. Educação a distância. 5. ed. Reimpressão. Campinas: Autores Associados, 2009.

BELUZO, M. F.; TONIOSSO, J. P. O Mobral e a alfabetização de adultos: considerações históricas. Cadernos de Educação: Ensino e Sociedade, Bebedouro-SP, 2 (1):196-209, 2015. Disponível em:

$<$ http://unifafibe.com.br/revistasonline/arquivos/cadernodeeducacao/sumario/35/0604201520 0716.pdf>. Acesso em: 28 jan 2016.

BRASIL. Lei $\mathrm{n}^{\circ}$ 9.394, de 20 de dezembro de 1996. Estabelece as diretrizes e bases da educação nacional. Diário Oficial [da República Federativa do Brasil], Brasília, DF, v. 134, n. 248, 23 dez. 1996. Seção I, p. 27834-27841. Disponível em:

$<$ http://www.planalto.gov.br/ccivil_03/LEIS/L9394.htm>. Acesso em: 15 jul. 2015.

COSTA, M. L. F. Educação a Distância no Brasil. In: COSTA, M. L. F. (org.). Educação a Distância no Brasil: Avanços e Perspectivas. 1. ed. Maringá: Eduem, 2013.

GIL, A. C. Métodos e técnicas de pesquisa social. 5.ed. São Paulo: Atlas, 1999.

GOUVÊA, G.; C. I. OLIVEIRA. Educação a Distância na formação de professores: viabilidades, potencialidades e limites. 4. ed. Rio de Janeiro: Vieira e Lent. 2006.

GUAREZI, R. C. M.; MATOS, M. M. Educação a distância sem segredos. 1. ed. Curitiba: InterSaberes, 2012. Disponível em:

$<$ http://cesumar.bv3.digitalpages.com.br/users/publications/9788582123225/pages/-2>.

Acesso em: 10 jun. 2015.

LAVILLE, C.; DIONNE, J. A construção do saber: manual de metodologia da pesquisa em ciências humanas. Belo Horizonte: UFMG, 1999.

LOPES, L. F.; FARIA, A. A. O que e o quem da EaD: história e fundamentos. 1.ed. Curitiba: InterSaberes, 2013. Disponível em:

$<$ http://cesumar.bv3.digitalpages.com.br/users/publications/9788582127228/pages/-2>. Acesso em: 15 jun. 2015.

MAIA, C.; MATTAR, J. ABC da EaD. 1. ed. São Paulo: Pearson Prentice Hall, 2007. Disponível em:

$<$ http://cesumar.bv3.digitalpages.com.br/users/publications/9788576051572/pages/_1>. Acesso em: 10 jun. 2015.

MOORE, M.G.; KEARSLEY, G. Educação a Distância: Uma visão integrada. Trad. Roberto Galman. São Paulo: Censage Learning, 2008. 
MORAN, J. M. O que é educação a distância. Universidade de São Paulo. Disponível em: < http://www2.eca.usp.br/moran/wp-content/uploads/2013/12/dist.pdf>. Acesso em: 15 out. 2015.

PEREIRA, E. W.; MORAES, R. A. História da educação a distância e os desafios na formação de professores no Brasil. In: SOUZA, A. M.; FIORENTINI, L. M. R.;

RODRIGUES, M. A. M. (orgs.). Educação Superior a Distância: Comunidade de

Trabalho e Aprendizagem em Rede (CTAR). Brasília: Universidade de Brasília, Faculdade de Educação, Editora da Universidade de Brasília, 2010.

PETERS, O. A Educação a Distância em Transição: Tendências e Desafios. Trad. Leila Ferreira de Souza Mendes. São Leopoldo: Unisinos, 2009.

SARAIVA, Terezinha. Educação a distância no Brasil: lições da história. Em aberto. Brasília, ano 16, n. 70, p.17-27, abr./jun. 1996.

UNICESUMAR - Centro Universitário de Maringá. Disponível em:

$<$ http://www.unicesumar.edu.br/graduacao/missao.php>. Acesso em 17 out. 2015.

UNICESUMAR - Centro Universitário de Maringá. Metodologia EaD. Maringá:

Departamento de Processos e Qualidade - Núcleo de Ensino a Distância, 2015.

UNICESUMAR - Centro Universitário de Maringá. Projeto Pedagógico do curso de graduação em Pedagogia Licenciatura. Maringá: NEAD - Núcleo de Educação a Distância, 2014.

Universidade Aberta do Brasil - UAB. Disponível em:

$<$ http://uab.capes.gov.br/index.php/sobre-a-uab/historico> Acesso em: 02 ago. 2015

VIDAL, E. M.; MAIA, J, E. B. Introdução a Educação a Distância. 1.ed. Fortaleza: RDS, 2010.

VILAÇA, M. L. C. Educação a Distância e Tecnologias: conceitos, termos e um pouco de história. Revista Magistro: Revista do Programa de Pós-Graduação em Letras e Ciências Humanas - UNIGRANRIO, Rio de Janeiro, v. 1, n. 2, p. 89-101, 2010

YIN, R. K. Estudo de caso: planejamento e métodos. 2.ed. Porto Alegre: Bookman, 2001. 